\title{
Temporal Restriction and Interest for the Elderly on Cultural Participation. The Case of Spanish Performing Arts 2019
}

\author{
Blas Díaz León* (D), Ignacio Martínez Fernández**iD, Luis Palma Martos**
}

\begin{abstract}
This paper discusses the relationship of cultural participation in performing arts with the manifested interest. Using the data set from the Cultural Habits and Practices Survey 2018-2019 a binary probit model has been applied for the analysis. Emphasizing the role of aging in participation, especially for the group of the elderly and very old. The age variable is one of the most difficult variables to apprehend, in which the cohort effects, age itself and period should be considered. This paper is an approach to the study of the aging effect on cultural participation, which would be continued with the analysis of the Surveys in previous years. This work shows that there is no homogeneous behavior between participation and interest within the different performing arts. Presenting some of them differentiating features.
\end{abstract}

Keywords: performing arts; participation; interest; binary probit model; elderly population.

JEL classification: J14, Z11.

\section{INTRODUCTION}

Cultural consumption has been a recurring subject of study in Cultural Economics since the very beginnings of the discipline. Analyzing the characteristics of the participants or the burdens to consumption are aspects frequently considered by various cultural disciplines from different approaches with various methodologies. As stated in Foote (2002), from a research point of view, it's necessary to keep the public or participating population at the center of theoretical cultural analysis, to improve the understanding of the underlying motivations and patterns within reach and the duration of such cultural participation and consumption. This work is part of a larger research project on the cultural consumption for the elderly in Spain. Studies of consumption for the elderly, understood as the population over 65 years of age, are of special relevance by themselves. In the first place, due to the weight of this group in Spain,

\footnotetext{
"Departamento de Economía e Historia Económica de la Universidad de Sevilla, Spain; e-mail: blasdiazleon@hotmail.com (corresponding author)

** Departamento de Economía e Historia Económica de la Universidad de Sevilla, Spain; e-mail: ignmarfer1@ gmail.com.

***** Departamento de Economía e Historia Económica de la Universidad de Sevilla, Spain; e-mail lpalma@us.es.
} 
since as January $1^{\text {st }}, 2021$, those over 65 years of age, according to the INE, represent $19.77 \%$ of the population. Secondly, due to the very effect of the natural aging process, this causes these age groups to increase in absolute and relative terms in the population. Just because of the size of the group itself, it makes it especially relevant for the promotion and design of cultural activities and policies.

It is in this area that the research project of which this article is part is included, whose purpose is to know different aspects of cultural participation that serve as support to the institutions and entities, both public and private that develop cultural policies. The aspects on which special attention is paid in this work are the existence of a temporal restriction in cultural participation and the influence of the social environment. Cultural institutions need to know consumer's behavioral patterns to make relevant decisions. It is considered as participant, regardless of the frequency, those who have attended a cultural event at least once in the last year. For this paper, the population analyzed is not limited exclusively to the elderly; all age cohorts from 15 years of age are considered. This is so since the elderly serve as a reference in the interpretation of the data as they have more free time, and as has been indicated. The elderly presents a double quality that is of interest for this analysis. In theory, they are the ones with the freest time, and in principle, they have had the opportunity to acquire a greater appreciation for cultural assets through past consumption.

Cultural goods as a category is make up a wide variety differentiated, and it is known that they present a huge typology. Despite sharing common characteristics, they also have great differences between them. The very definition of cultural or artistic property is far from obvious, as referred to in McCain (2006). Among the common characteristics, the fact that they are consumed in "free time" stands out. This characteristic is shared with other leisure goods, but they do not have to be considered as cultural goods. The socializing effects derived from the consumption of leisure and cultural goods are presented as a common characteristic for these two categories of goods. The differences between leisure and cultural goods are such that they shape different consumer's behavior. A differentiation between cultural consumption and leisure is the very aim of its consumption. The active or passive position of the consumer in the act of consumption is important to define what a cultural consumption is. The effort of the cultural consumer is related to the need for knowledge to enjoy the cultural goods. The acquisition of knowledge for the consumption and formation of cultural taste requires a time and preparation. That is why it can be said that cultural consumption is time intensive; it takes time to acquire prior knowledge in addition to the time for the actual consumption.

By establishing cultural consumption as time-intensive, and considering the temporal restriction as a hypothesis, it is justified that this work is limited to the performing arts and live classical music concerts ${ }^{1}$, since its participation is time-intensive. Those called "high culture" have common characteristics that are different from the rest of cultural goods and services. In Falk and Katz-Gerro (2016) it is already indicated that (...) they deserve a separate analysis; as indicated by previous research (Katz-Gerro and Lopez-Sintas 2013), they measure participation in a different environment, referring to studies on performing arts and the rest of cultural goods. All of them have similar characteristics; they are consumed live, away from home, in a specific, non-divisible period, and require a certain training to be appreciated. In Aguado, Palma, and Pulido (2017) characterize these goods as those cultural goods and services that are produced at the very moment of their consumption, which requires a great deal of time and generally occurs outside the home. Despite these common characteristics, can be also find the lack of homogeneity in the participation, because although 
similar, they are goods with different characteristics. In the case of the performing arts, time plays an added role; the consumption of them cannot be divided nor segmented but must occur at a specific time.

Even taking the time restriction as a reference, this work has not made use of the data from the INE (Spanish National Statistics Institute) Time Use Survey but relies on the Survey of Cultural Habits and Practices (EHPC for its name in Spanish) for Spain 2018-2019 carried out by the Ministry of Culture and Sports, understanding that it is a more specific survey for studies of cultural participation. The survey is limited to the population resident in Spain; it also refers to the last period surveyed before the Covid-19 outbreak, so the data from this survey will serve as a reference to evaluate in future studies the effects produced on postCovid cultural participation.

As indicated above, cultural consumption requires an active posture in the consumer, an effort, and intentionality. Cultural participation is an intentional act that aims to increase the participant's information and cultural heritage (UNESCO, 2006) ${ }^{2}$; therefore, in addition to the usual variables, the inclusion of the variable expressed interest is considered in the participation model in the different performing arts. In addition, its use and its breakdown between specific interest and interest in the rest of the arts support the interpretation of the results in relation to the existence of a time restriction on the cultural participation in performing arts.

Another reason that justifies the use of the variable interest in the model is the possible lack of it as a barrier for participation; thus, in the opinion of Ateca Amestoy ${ }^{3}$, the lack of interest is the main barrier to cultural participation. In the same sense, Prieto Rodríguez, Pérez Villadóniga, and Suárez Fernández (2018) indicate that the lack of interest, the first barrier to cultural participation, is greater in activities that require greater training in the arts and could be avoided through better cultural education. For this reason, in this work it is understood that the interest expressed by a good would be a variable to consider in the study of cultural consumption. As it is an intentional consumption, the knowledge that one has of the good will increase the interest in it. This knowledge of the good depends on the training and previous consumptions. Age could increase the probability of previous consumptions, and if they were positive, interest in the performing arts.

In this work, participation models are presented for each of the performing arts contemplated, by age groups, which allows visualizing whether participation in the performing arts is homogeneous for each activity and each age group. Or if, on the contrary, there are no homogeneous consumption patterns for each one of the arts and for age groups.

In the models developed in this paper, other variables that represent relevant characteristics and have been accessed have been included. The different studies of cultural consumption, in general, coincide in considering as independent variables of consumer behavior, various categories. Among which are socio-economic variables, such as income level or employment status. There are geographical variables such as the size of the municipality, the country, and the region and even, in some cases, the neighborhood of residence. Another group of variables is made up with the personal characteristics of the individual, such as level of education, gender, personal situation, age and even, in some cases, race and ethnicity, nationality or family relationship. Finally, other variables, which can be called "structural", can have a significant weight in the consumption of cultural goods and services (Aguado \& Palma, 2015). The habit and role of artistic experience acquired with 
parents in the consumption of culture could also be considered; as is done in the work of Abbé-Decarroux (1995), and the creative field in which the consumer operates.

The variables that have been included in the model presented are gender, age, work situation and family situation, educational level, and interest in its double aspect, specific for an art or also for the rest of the arts. It was not possible to include the income variable, nor other variables related to the geographical situation or health situation. It can be understood that this last variable would be important mainly for the elderly group. As for the education variable, it is the only one that has been considered as a trainer of cultural capital, not having considered other types of circumstances that would be part of it and would configure it. From the EHPC data, a variable that approximates the cultural capital can be obtained, but its development has been left for later works in which the interest with the formation of cultural capital will be related, through past experiences and specific training; that is why the completed general formal training is left as a proxy for cultural capital.

The aim of this paper is to find evidence of the temporal restriction from the EHPC and the possible effects of the social environment on the behavior of the cultural consumer. Is there a time restriction? Are the active workers more likely to participate? And are those with burdens less likely to participate? Is interest a determining element in participation in the performing arts? Of the very old, they show less interest in the performing arts? What roles do social relations between the elderly have in their cultural participation? For the data analysis, a binomial probit regression model has been used.

As relevant contributions, it is established that working and family environments are important in the formation of cultural participation. Since the personal variable is defined as defined in this work, it allows us to appreciate the possible effect of loneliness in the very old, for which having burdens (not being alone) increases the probability of participating. For all age groups in all arts, the temporal restriction on participation is perceived, except for classical music concerts. With the established modeling, it is not possible to determine the existence of a temporal restriction for the concert activity.

The next section present a literature review on the variables considered in this work. It is followed by a third section, empirical in nature, which describes the database that has been used, the modeling, and the analysis and discussion of the results; finally in the fourth section the conclusions and future research lines are presented.

\section{LITERATURE REVIEW}

One of the main conclusions established in studies on cultural participation in performing arts is the small population that participates. According to the data managed by the EHPC for Spain in 2018-2019, 31.47\% of the population over 15 years of age has participated in any of the performing arts at least once in the last year. Considering the population over 15 years old as of January 1, 2019, according to the INE, it could be indicated that the population residing in Spain over 15 years old that participates in any of the performing arts is $12,590,185$.

In this work only participation is studied, and not its frequency. The variables observed have different effects on participation and frequency (Borgonovi, 2004). Only participation is considered, understood as attendance in the last year. Frequency studies tend to limit their object of analysis to the consumer population of a given cultural good, as in Heredia-Carroza, Palma Martos, and Marin (2020) in the case of flamenco, which limits its population to results 
as consumers. Flamenco is an artistic activity that is popular in nature, it presents common characteristics with the performing arts that is the object of this work. There is a consensus on which are the most significant variables in the consumption of cultural goods and services and the effects on participation. Education is the variable that has the greatest influence on participation, the higher the education, the greater the probability of cultural consumption, especially in the performing arts. Income also has a positive influence on participation, although there are certain considerations about it, because it has on leisure time. Age is of central importance as a factor that affects cultural consumption, and is thus considered in various studies, among which Scherger (2009) can be highlighted. In Hallmann, Artime, Breuer, Dallmeyer, and Metz (2017) there is an interesting description of the role of age in different practices. Age has a positive effect on participation, but it is modulated by the life cycle and the effects of human capital. In Wen and Cheng (2013) it is said that age does not have a monotonous relationship with attendance, since there are life cycle effects and human capital effects. A similar idea can be seen in Courty and Zhang (2018), when they establish that there is no clear pattern in the activities, there are life cycle effects or generational effects. Normally, people go through different situations throughout life, they begin their training, they become emancipated and have obligations to their children, the children become emancipated and at the end of their lives they are left alone. In Ateca-Amestoy (2008), it is stated that age has a positive effect on both participation and frequency for theater, contrary to what is indicated by Borgonovi (2004). When the effect of age is analyzed, there is a consensus that it is the most difficult variable to study, since a distinction must be made between age, period, and cohort effects. For the study of these differences there are different works; among others those of Glevarec, Nowak, and Mahut (2020); Miles and Sullivan (2012); Reeves (2014); Van den Broek (2013). The focus on age is placed especially due to the double quality of the elderly, the greater availability of free time to devote to cultural participation and the greater probability of having acquired a greater appreciation through previous consumption.

In relation to other variables studied in cultural participation, women have a greater probability of participating in the performing arts (Suárez-Fernández, Prieto-Rodríguez, \& Pérez-Villadoniga, 2020); or as indicated in Grisolía, Willis, Wymer, and Law (2010), many studies show that women are more involved in theater. The cultural consumer profile also has an urban component and high levels of cultural capital. Understanding by cultural capital both the formal educational level and the particularly cultural level.

For the geographic variables, location, in Brook (2013) the role of access is studied in the case of opera in London; in which it is indicated that, according to the literature, distance would greatly influence attendance, and applying grouped logistic regression models, she establishes that the omission of access to the opera in London is significant. In Diniz and Machado (2011), for the case of Brazil, it is indicated that geographic variables influence more than the individual characteristics of the consumer and highlight the importance of the historical-cultural background and the offer among those who consume the most. Other variables such as race and ethnicity are collected in the work by Buigut and Amaize (2020), and nationality or family relationship in Upright (2004).

The variable interest that is relevant in this work presents discussion between authors. Thus, in Suárez-Fernández et al. (2020), it is indicated that interest could be an argument of the utility function but not a determinant of its functional form, proposing that the more education, the greater the cultural capital and therefore greater interest. On the other hand, in 
the work of De la Vega, Suarez-Fernandez, Boto-Garcia, and Prieto-Rodriguez (2020) the self-declared interest in the formulated study model is considered.

The theoretical framework of the consumption of cultural goods also highlights the importance of time in consumption, with the work of Becker (1965) being a reference. Cultural goods are studied in dynamic consumption models; they are goods with characteristics of addictive goods. Both in the theories of cultural consumption capital by Stigler and Becker (1977) and rational addiction by Becker Becker and Murphy (1988), as well as in the taste formation by Lévy-Garboua and Montmarquette (1996), past consumption influences current and future consumption. In Abbé-Decarroux (1993) it is said that our results confirm the idea that past consumption of live art affects future consumption and that the process of formation of preferences is one of the essential determinants. Age facilitates the possibility of past consumption by increasing cultural capital and the formation of taste through learning by consuming or rational addiction models. A brief state of the art theoretical question can be seen in Levy-Garboua and Montmarquette (2005) and McCain (2005).

\section{EMPIRICAL ANALYSIS}

\subsection{Dataset and variable descriptions}

For this paper, data from the Survey of Cultural Habits and Practices of Spain (EHPC) 2018-2019 have been used. This survey has 15,455 observations for residents in Spain over 15 years of age. The data were collected between March 2018 and February 2019. They are the latest data prior to the pandemic that developed in 2020. Therefore, they can serve as a reference for future research on the effects of the Covid-19 health crisis on participation in the performing arts.

For the labor situation variable, two different groups have been considered, the active group and the non-active group. Seven different work situations are presented in the survey: working; unemployed; retired or retired from work / pensioner; permanently disabled; student (not working); dedicated to housework; and others. Those who respond to the survey as working or unemployed are considered as active, the rest of the situations are considered as non-active. In the preparation of the model, the active population has been coded with the value 1 .

The personal situation has been configured according to the existence of family responsibilities or not. In the survey, 8 different personal situations are established; single without children in his parents' house; independent single, divorced, separated or widowed with no dependent children; single, divorced, separated or widowed with dependent children; married or in a couple without children; married or with a partner with a child under 18 years of age (even if they also have other children); married or with a partner with children aged 18 or over at home; married or with a partner with children aged 18 or over who do not live at home; others. This is how those who do not have family responsibilities are distinguished, such as singles without children who live with their parents and singles without children. This group has been assigned a value of 1 in the model. The rest of the personal situations are coded as 0 . Thus, the variable has been modeled, trying to focus the study on the individual decision to participate, therefore, married subjects are included among those who have responsibilities or burdens, since the decision to participate can be very determined, mediated by the couple, having children or not. 
The education variable is configured as shown in the Survey, since 10 levels are established from lowest to highest training. Corresponding 1 to those who have attended to school for less than 5 years, to 10 corresponding to $\mathrm{PhD}$ studies.

Age, which does not appear as such in the survey data, is calculated from the year of birth. It is used as an approximation, because the data were obtained between the last months of 2018 and the beginning of 2019. Seven age groups are considered, from the first 15-24 to those over 75. Gender has been coded as 1 for women and 0 for men.

Interest is the self-declared interest by the respondents and takes values between 0 and 10 to the direct question about the interest they have in the different performing arts. The question formulated in the survey is: how would you rate your interest in the following cultural activities?

Variables referring to income, professional status, health status and population or nationality have not been considered since the data from the corresponding survey questions have not been available.

\subsection{Modeling and analysis of the results}

Since participation in performing arts is the object of study, everyone who has attended at least once in the last year will be considered a participant. This definition of participation in the performing arts is usually used for the study of participation, an example of this is Katz-Gerro, Raz, and Yaish (2009), Chan and Goldthorpe (2005), Espinosa Espinosa and Palma Martos (2019), Upright (2004); although in other studies the number of times attended is also used, distinguishing participation from frequency. For this reason, it has been chosen to define a model of cultural participation in performing arts with the variables sex, employment situation, personal situation, educational level, age, and average interest in the performing arts ${ }^{4}$.

As a preliminary step to the econometric study, Table no. 1 shows the correlations between the variables participation and interest by age groups, thus establishing how related the variables are, and if said relationship is the same for any age group and performing arts. The first thing that emerges is that all the correlations are positive. Second, that they are not homogeneous for all the arts; thus, three different groups can be established; those with a weak positive relationship (Opera, Ballet and Concerts), a null or insignificant relationship (Zarzuela) and a relatively high positive relationship (Theater). It is the Theater, for the age group 25-34 years, the one that presents the highest correlation with a value of 0.42540035 . The very old age group tends to show lower correlations than the rest of the age groups. These data may indicate that interest is a variable to consider, but that it may not be the decisive one in participation in the performing arts. In this case, it can be doubted that the handicap of cultural participation is the lack of interest, at least in the performing arts. For this reason, if the interest is related to the cultural capital and to the previous assistances that make up the cultural capital itself and the appreciation of the arts, these two variables, despite being very important, would not be decisive in participation. Therefore, there is room for other determining factors of assistance, such as structural factors that depend more on supply rather than demand. 
Díaz León, B., Martínez Fernández, I., Palma Martos, L.

Table no. 1 - Participation / Interest Correlations

\begin{tabular}{lccccc}
\hline & Theater & Opera & Ballet & Zarzuela $^{5}$ & Concerts \\
\hline TOTAL & 0.36629951 & 0.24683963 & 0.29158019 & 0.18064238 & 0.28082866 \\
\hline $\mathbf{1 5 - 2 4}$ & 0.35169919 & 0.22628608 & 0.32391163 & 0.11050444 & 0.28799778 \\
\hline $\mathbf{2 5 - 3 4}$ & 0.42540035 & 0.27440192 & 0.28382155 & 0.15947943 & 0.27533126 \\
\hline $\mathbf{3 5 - 4 4}$ & 0.37301334 & 0.22063105 & 0.30002235 & 0.15421324 & 0.21551190 \\
\hline $\mathbf{4 5 - 5 4}$ & 0.34924329 & 0.21642732 & 0.28632698 & 0.15905647 & 0.27417495 \\
\hline $\mathbf{5 5 - 6 4}$ & 0.36720103 & 0.27543785 & 0.31236129 & 0.19286531 & 0.28929907 \\
\hline $\mathbf{6 5 - 7 4}$ & 0.34914522 & 0.28689661 & 0.26979075 & 0.19564591 & 0.32328529 \\
\hline $\mathbf{7 5}$ & 0.29287222 & 0.21518859 & 0.24184280 & 0.14203061 & 0.28386425 \\
\hline
\end{tabular}

Source: own elaboration. Data EHPC 2018-2019.

The correlation between participation for the different performing arts has also been calculated, as well as the correlation between interests in the different performing arts. In the following Table no. 2 they can be observed.

Table no. 2 - Correlation analysis

\begin{tabular}{|c|c|c|c|c|c|}
\hline \multicolumn{6}{|c|}{ Participation correlation interest correlation total sample } \\
\hline Opera & Ballet & Zarzuela & Concerts & & \\
\hline 0.6494 & 0.6575 & 0.5922 & 0.5273 & I & \multirow{2}{*}{ Theater } \\
\hline 0.2106 & 0.2864 & 0.1600 & 0.2582 & $\mathrm{P}$ & \\
\hline & 0.7533 & 0.8054 & 0.6314 & I & \multirow{2}{*}{ Opera } \\
\hline & 0.2475 & 0.2844 & 0.3108 & $\mathrm{P}$ & \\
\hline & & 0.7185 & 0.5712 & $\mathrm{I}$ & \multirow{2}{*}{ Ballet } \\
\hline & & 0.1576 & 0.2301 & $\mathrm{P}$ & \\
\hline & & & 0.5672 & $\mathrm{I}$ & \multirow{2}{*}{ Zarzuela } \\
\hline & & & 0.1783 & $\mathrm{P}$ & \\
\hline
\end{tabular}

Source: own elaboration. Data EHPC 2018-2019.

From the above data, the high degree of correlation in interest in the different performing arts can be deduced, which far exceeds the correlation in participation. In all the performing arts the correlation in interest can be considered high or very high, since the lowest of the values is found in the correlation between concerts and theater, which reaches 0.5273 ; while the highest of the values is found in the Zarzuela and the Opera, reaching a correlation of 0.8054 .

On the other hand, a large difference is observed with the correlation in participation, whose values are much smaller. The highest value achieved is the one corresponding to Opera and Concerts, 0.3108 , while the smallest is 0.1576 for Ballet and Zarzuela. These correlations in participation are always positive, but it is a weak correlation, or in many cases negligible.

This difference between the correlations of participation and interest is maintained when calculating by age group, with slight nuances. For example, in the group of those over 75 years of age, the correlations of both participation and interest are slightly higher than those of the total sample.

From the previous correlations, since the values corresponding to interest are greater than those of participation, this may suggest that the theory of cultural omnivores is more evident in the interest manifested by the consumer than in participation; Being that affected by income restrictions and from this work, of time that is one of the study hypotheses. Thus, there are barriers to consumption that may not be determined by interest. 
Scientific Annals of Economics and Business, 2021, Volume 68, Special Issue, pp. 35-52

Once the database was presented and a first exercise was carried out to see the correlations between some relevant variables, a binomial probit model has been proposed ${ }^{6}$. In the model, the dependent variable is participation, considering the others as regressors.

Table no. 3 - Initial model

\begin{tabular}{|c|c|c|c|c|c|c|c|c|}
\hline & Sample & $15-24$ & $25-34$ & $35-44$ & $45-54$ & $55-64$ & $65-74$ & 75> \\
\hline$\alpha$ & $(-1.3277)$ & $(-1.1660)$ & $(-1.9995)$ & $(-2.0137)$ & $(-1.8480)$ & $(-1.7239)$ & $(-1.7523)$ & $(-2.2187)$ \\
\hline Age & $\begin{array}{c}-0.0024 \\
(-0.0071) * * *\end{array}$ & & & & & & & \\
\hline Gender & $\begin{array}{c}0.0046 \\
(0.0137)\end{array}$ & 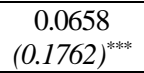 & $\begin{array}{c}0.0049 \\
(0.0143)\end{array}$ & $\begin{array}{c}0.0247 \\
(0.0685)\end{array}$ & $\begin{array}{c}0.0166 \\
(0.0466)\end{array}$ & $\begin{array}{c}0.0026 \\
(0.0075)\end{array}$ & $\begin{array}{c}-0.0116 \\
(-0.0350)\end{array}$ & $\begin{array}{c}-0.0040 \\
(-0.0233)\end{array}$ \\
\hline $\begin{array}{l}\text { Employment } \\
\text { situation } \\
\end{array}$ & $\begin{array}{c}-0.0239 \\
(-0.0702)^{* * *} \\
\end{array}$ & $\begin{array}{c}-0.1015 \\
(-0.2807)^{\text {**** }}\end{array}$ & $\begin{array}{c}-0.0450 \\
(-0.1284) \\
\end{array}$ & $\begin{array}{c}0.1086 \\
(0.249)^{* * * *} \\
\end{array}$ & $\begin{array}{c}0.0714 \\
(0.2096)^{* * *} \\
\end{array}$ & $\begin{array}{c}0.0161 \\
(0.0454) \\
\end{array}$ & $\begin{array}{c}-0.0037 \\
(-0.0113) \\
\end{array}$ & $\begin{array}{c}0.1587 \\
(0.6373) \\
\end{array}$ \\
\hline $\begin{array}{l}\text { Personal } \\
\text { situation }\end{array}$ & $\begin{array}{c}-0.0134 \\
(-0.0398) \\
\end{array}$ & $\begin{array}{c}0.0408 \\
(0.1114) \\
\end{array}$ & $\begin{array}{c}0.0814 \\
(0.2422)^{* * * *} \\
\end{array}$ & $\begin{array}{c}0.0112 \\
(0.0309) \\
\end{array}$ & $\begin{array}{c}-0.0280 \\
(-0.0798)\end{array}$ & $\begin{array}{c}-0.0652 \\
(-0.1898)^{\text {*** }}\end{array}$ & $\begin{array}{c}0.0135 \\
(0.0405) \\
\end{array}$ & $\begin{array}{c}-0.0407 \\
(-0.2483)^{* * * *} \\
\end{array}$ \\
\hline $\begin{array}{l}\text { Level of } \\
\text { studies }\end{array}$ & $\begin{array}{c}0.0375 \\
(01103)^{* * * *} \\
\end{array}$ & $\begin{array}{c}0.0044 \\
(0.0118) \\
\end{array}$ & $\begin{array}{c}0.0384 \\
(0.1124)^{* * * *} \\
\end{array}$ & $\begin{array}{c}0.0429 \\
(0.1189)^{* * * * *} \\
\end{array}$ & $\begin{array}{c}0.0433 \\
(0.1215)^{* * * *} \\
\end{array}$ & $\begin{array}{c}0.0449 \\
(0.1262)^{* * * *}\end{array}$ & $\begin{array}{c}0.0372 \\
(0.1123)^{* * * * *} \\
\end{array}$ & $\begin{array}{c}0.0186 \\
(0.1067)^{* * * *} \\
\end{array}$ \\
\hline $\begin{array}{l}\text { Interest in the } \\
\text { performing } \\
\text { arts }\end{array}$ & $\begin{array}{c}0.0542 \\
(0.1595)^{* * * *}\end{array}$ & $\begin{array}{c}0.0608 \\
(0.1629)^{\text {**** }}\end{array}$ & $\begin{array}{c}0.0659 \\
(0.1927)^{* * * * *}\end{array}$ & $\begin{array}{c}0.0477 \\
(0.1321)^{* * * *}\end{array}$ & $\begin{array}{c}0.0460 \\
(0.1290)^{* * * * *}\end{array}$ & $\begin{array}{c}0.0543 \\
(0.1528)^{* * * *}\end{array}$ & $\begin{array}{c}0.0567 \\
(0.1710)^{* * * *}\end{array}$ & $\begin{array}{c}0.0337 \\
(0.1931)^{\text {**** }}\end{array}$ \\
\hline $\begin{array}{l}\text { adjusted R- } \\
\text { squared }\end{array}$ & 0.1349 & 0.0828 & 0.1505 & 0.1056 & 0.1126 & 0.1425 & 0.1432 & 0.1889 \\
\hline $\begin{array}{l}\text { Correct } \\
\text { prediction }\end{array}$ & $72.1 \%$ & $66.2 \%$ & $72.9 \%$ & $68.8 \%$ & $70.0 \%$ & $70.5 \%$ & $74.2 \%$ & $86.0 \%$ \\
\hline
\end{tabular}

Note: $*, * *, * * *$ represent significance at $10 \%, 5 \%$ and $1 \%$ respectively.

Source: own elaboration. Data EHPC 2018-2019.

Applying the model to the 15455 observations has a prediction grade of $72.1 \%$. It shows that age and employment status are significant with negative slopes. Age reduces the probability of participation in the performing arts by 0.24 percent. Similarly, being in an active situation reduces the probability of participating by 2.39 percent.

The level of studies and interest in the arts in general are significant with a positive slope. The variable interest has a greater influence than educational level on the behavior of the dependent variable. Thus, an increase in interest increases the probability of participating by 5.42 percent, while an increase in the level of studies increases the probability of participating by 3.75 percent. Gender and personal situation are not significant for the model in the full sample.

To apply this model by age group, the age variable has been suppressed. The degree of prediction gravitates around that of the model for the sample, ranging from a correct prediction of $66.2 \%$ for the youngest group to $86.0 \%$ for the very old.

Interest is significant in all age groups, such that in any group an increase in interest increases the probability of participation. The same behavior is experienced by the level of studies, except for the 15-24 age group, for which it is not significant. It is also observed that the slopes of the interest variable are greater than those of the level of education. It can be thought that higher educational levels correspond to a greater degree of interest in the performing arts, as indicated by Prieto Rodríguez et al. (2018); for whom a higher educational level leads to an increase in cultural capital, which in turn increases interest. Two effects can be derived from the increase in educational levels; higher education is related to increases in training and income 
levels. Increases in education shape social capital and this positively affects cultural consumption, insofar as the necessary prior education of the consumer to appreciate the good is characteristic of this market. It is not clear that the higher the income, the greater the participation, since the higher the income, the less time is spent on leisure and culture. The fact that in all the age groups, including the elderly, where there is no time restriction, the interest variable has slopes greater than those of the level of education leads us to think that the interest, in addition to being determined by the educational level, training and knowledge of the performing arts, would have components other than the previous ones, such as induced interest, a replication effect or mimicry effect, all components related to the sphere in which the individual develops. In Ateca-Amestoy (2009) "the attendance to cultural performances is a typically social activity and it is to be expected that the behavior of the closest people has some kind of effect on the individual's cultural consumption". Also, in Palma, Palma, and Aguado (2013) for the case of the Spring Fiestas in Seville, it is indicated that individual preferences may be sensitive to the consumption of the group to which they belong.

Gender is only significant for the youngest age group. Thus, in this age group, the model indicates that being a woman increases the probability of participation by 6.58 percent, while for the rest of the groups, gender would not be significant.

The employment status variable shows an interesting behavior among the different age groups. For the sample it is significant and negative. This is also the case in the younger age group, in such a way that among this group the active ones have a lower probability of participating than the non-active ones; this can be explained by the fact that these are the first years of incorporation to work, which may be combined with studies. As a result, there is less time to devote to culture. In the next age group, this variable cease to be significant, to become significant again with a positive slope for the population between 35 and 54 years of age; thus the active are more likely to participate in performing arts than the non-active in these age groups. The effect of a certain group sense of belonging can be found in this behavior. Despite having less free time, the fact of being active implies a greater probability of participating. After the age of 55, the variable ceases to be significant in participation, which may suggest that workers are in a work situation in which they do not need to be reflected in the work group. In Grisolía et al. (2010) when evaluating the degree to which the theater relates to the local population, the effect of different occupations on theater attendance patterns is analyzed; higher professional occupations such as accountants, clergymen, doctors, and lawyers are more likely to attend than other socio-economic groups. Lower technical and supervisory occupations and the unemployed are less likely to attend the theater. He also stresses that the role of the selfemployed needs more research, just as in the case of managerial professionals it is necessary to study which managerial groupings do and do not attend theatrical performances. For them, education is the most important factor, but without forgetting the occupational environment.

Personal situation, which is not significant for the full sample, is significant for the 25-34 age group. Having no burdens increases the probability of participation among this group by 8.14 percent. In contrast, it does not become significant again until the 55-64 and 75+ age groups, but in this case with negative slopes. These data may be highlighting the effect of loneliness. One of the reasons given for not attending more performing arts is not having someone to go with.

Starting with an initial regression model for the set of performing arts and their average interest, different regressions were performed for each of the performing arts and for each of the age groups. When tabulating the responses relating to work and personal situation, the difference between the working population and the population without dependents was 
established, this was done to be able to develop the analysis including a restriction on the use of time. Given that it can be assumed that the working population with dependents, in aggregate terms, has less time to participate in cultural activities; knowing that participation in the activities under study are time intensive (it is not possible to fragment their consumption over time), redefining the model on the basis of this time restriction, so that two new variables are included: interest in $a$ and interest in $n-a, a$ being the performing art to be observed.

Prior to analyzing the results of the five previous models, the regression is calculated for the sample. In this case, the difference is found in the inclusion of the age variable, giving rise to the following general model, the results of which are shown in Table no. 4 below.

Table no. 4 - General model

\begin{tabular}{|c|c|c|c|c|c|c|c|c|}
\hline & $\alpha$ & Age & Gender & $\begin{array}{c}\text { Employment } \\
\text { situation } \\
\end{array}$ & $\begin{array}{l}\text { Personal } \\
\text { situation } \\
\end{array}$ & $\begin{array}{l}\text { Level of } \\
\text { studies }\end{array}$ & $\begin{array}{l}\text { Specific } \\
\text { interest }\end{array}$ & $\begin{array}{c}\text { Interest } \\
\text { other arts }\end{array}$ \\
\hline Theater & 8043) & $\begin{array}{c}-0.0023 \\
(-0.0083)^{\text {**** }}\end{array}$ & $\begin{array}{r}-0.01 \\
(-0.062 \\
\end{array}$ & $\begin{array}{c}-0.0187 \\
(-0.0625)^{* *}\end{array}$ & $\begin{array}{c}0.0016 \\
(0.0060)^{\text {**** }}\end{array}$ & $\begin{array}{c}0.0263 \\
(0.0957)^{\text {**** }}\end{array}$ & $\begin{array}{c}0.0568 \\
(0.0261)^{* * * *}\end{array}$ & $\begin{array}{r}-0 . \\
(-0.0 \\
\end{array}$ \\
\hline Op & & $\begin{array}{c}0.0000 \\
(-0.0002) \\
\end{array}$ & -0.0 & $\begin{array}{r}-0.0 \\
(-0.22 \\
\end{array}$ & $\begin{array}{l}-0.0 \\
(-0.0 \\
\end{array}$ & $\begin{array}{c}0.0022 \\
(0.0946)^{\text {**** }}\end{array}$ & $\begin{array}{c}0.0058 \\
(0.2418)^{* * * *}\end{array}$ & $\begin{array}{r}-0 . \\
(-0 . \\
\end{array}$ \\
\hline Ball & 4043) & $\begin{array}{r}-0.00 \\
(-0.004 \\
\end{array}$ & $\begin{array}{r}0.0 \\
(0.0 \\
\end{array}$ & $\begin{array}{r}0.0 \\
(0.0 \\
\end{array}$ & $\begin{array}{r}-0.0 \\
(-0.0 \\
\end{array}$ & $\begin{array}{c}0.0073 \\
(0.0758)^{\text {**** }}\end{array}$ & $\begin{array}{c}0.0203 \\
(0.2085)^{* * * *}\end{array}$ & $\begin{array}{r}-0.0 \\
-0.0 \\
\end{array}$ \\
\hline Zarzu & & $\begin{array}{c}0.0000 \\
(0.0019)\end{array}$ & $\begin{array}{c}-0.0017 \\
(-0.1308)^{* * *}\end{array}$ & $\begin{array}{c}-0.0040 \\
(-0.2750)^{* * * *}\end{array}$ & $\begin{array}{c}-0.0001 \\
(-0.0140)\end{array}$ & $\begin{array}{c}0.0009 \\
(0.0700)^{\text {**** }}\end{array}$ & $\begin{array}{c}0.0030 \\
(0.2289)^{* * * *}\end{array}$ & $\begin{array}{c}-0.0005 \\
(-0.0395)^{* * *}\end{array}$ \\
\hline conce & $(-3.0764)$ & $\begin{array}{c}0.0004 \\
(0.0037)^{* * * *}\end{array}$ & $\begin{array}{c}-0.0133 \\
(-0.1197)^{* * * *}\end{array}$ & $\begin{array}{c}-0.0152 \\
(-0.1346)^{* * * *}\end{array}$ & $\begin{array}{c}0.0003 \\
(0.0034)\end{array}$ & $\begin{array}{c}0.0106 \\
(0.0956)^{\text {**** }}\end{array}$ & $\begin{array}{c}0.0178 \\
(0.1607)^{* * * *}\end{array}$ & $\begin{array}{c}0.0054 \\
(0.0489)^{* * * *}\end{array}$ \\
\hline
\end{tabular}

Note: $* * *, * * *$ represent significance at $10 \%, 5 \%$ and $1 \%$ respectively.

Source: own elaboration. Data EHPC 2018-2019.

The results of the model by activities for the total sample show a non-homogeneous behavior of the variables both in their significance and in the sign of their slopes. Age is only significant for theater and ballet with negative slopes, and concerts with a positive slope. Therefore, age increases the probability of participation in classical music concerts and reduces it in theater and ballet. The gender variable presents lower degrees of significance than age, but always has negative slopes; therefore, it reflects that being a woman reduces the probability of participating in the performing arts.

For all activities except ballet, employment status is significant and has negative slopes. It indicates that the active are less likely to participate than the non-active. This data may show the temporal restriction in the consumption of performing arts, since the active in principle have less time to dedicate to leisure. Having or not having burdens, which is observed in the personal situation, is not significant except in the case of theater, where not having burdens increases the probability of participation in this activity. Education and specific interest are significant in all the arts and present positive slopes. As it was seen in the initial model, it is also observed here for all the arts that the value of the slopes is greater for the variable interest than for education.

Contrary to what one might initially think, interest in the other arts is always significant and has a negative slope, except for concerts, whose slope is positive, and opera, for which it is not significant. Interest in the other arts makes participation in the specific art more difficult; thus, the probability of participating in theater decreases as interest in the other arts increases. This behavior of the variable can be considered as an effect of the consumer's time constraint. Table no. 5 shows the results of the different regressions carried out for the five performing arts by age group; the modeling considered did not include age as a variable. 


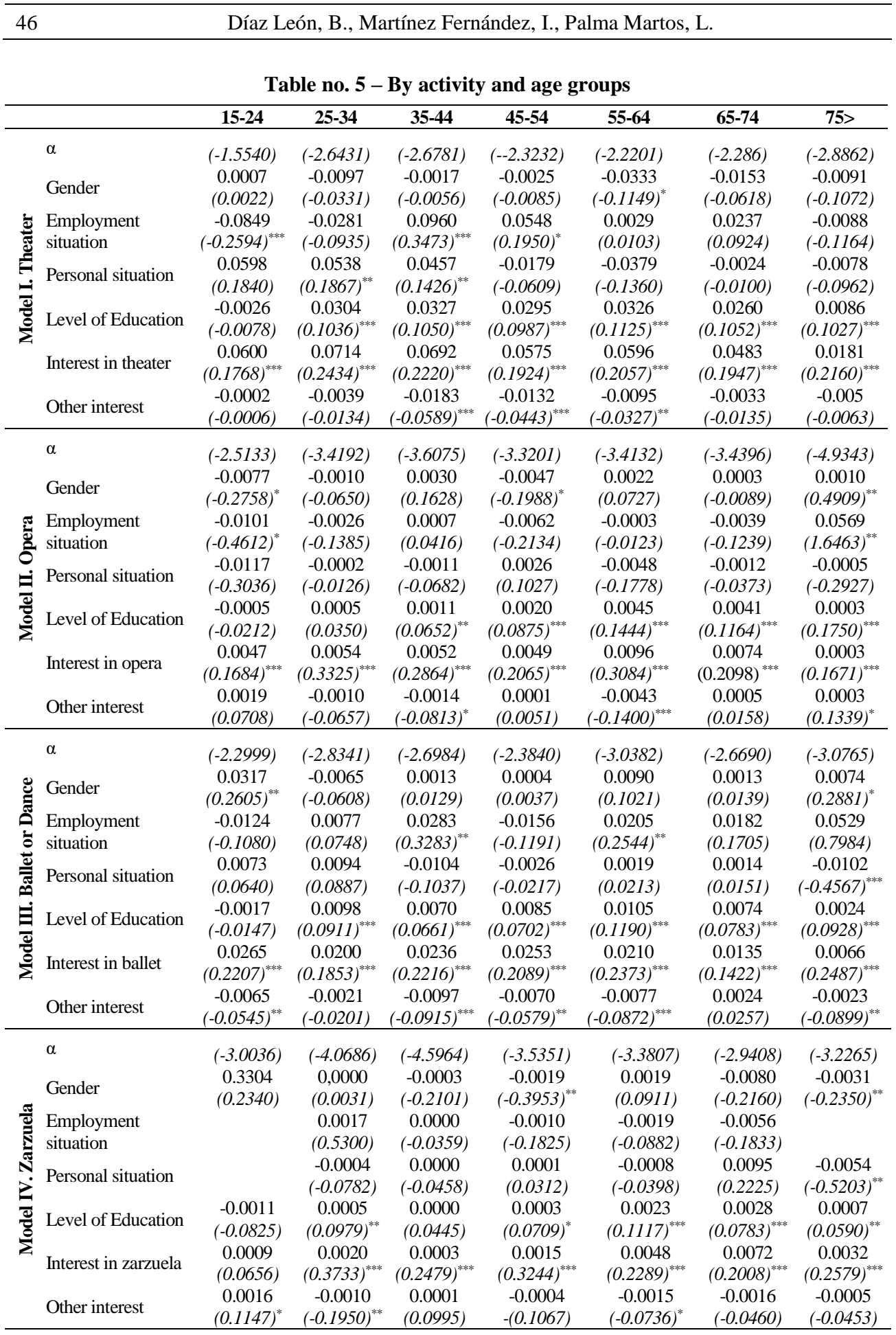




\begin{tabular}{|c|c|c|c|c|c|c|c|c|}
\hline & & e & ancu & nes & OIui & pecial & , pp. 5 & 52 \\
\hline & & $15-24$ & $25-34$ & $35-44$ & $45-54$ & $55-64$ & $65-74$ & 75> \\
\hline \multirow{13}{*}{ 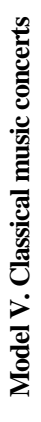 } & $\alpha$ & $(-2.6949)$ & $(-3.5101)$ & $(-3.1751)$ & $(-3.1074)$ & $(-2.7730)$ & $(-2.8649)$ & $(-2.9442)$ \\
\hline & & -0.0165 & -0.0156 & -0.0147 & -0.0055 & -0.0017 & -0.0117 & -0.0041 \\
\hline & Gender & $(-0.1889)^{*}$ & $(-0.2682)^{* * *}$ & $(-0.1463)^{*}$ & $(-0.0476)$ & $(-0.0105)$ & $(-0.0799)$ & $(-0.0621)$ \\
\hline & Employment & -0.0130 & -0.0237 & 0.0139 & 0.0058 & 0.0135 & -0.0379 & 0.1798 \\
\hline & situation & $(-0.1693)$ & $(-0.3254)^{* * *}$ & (0.1557) & $(0.0517)$ & $(0.0857)$ & $(-0.3088)^{* *}$ & $(1.0924)^{*}$ \\
\hline & & 0.0060 & 0.0120 & 0.0036 & -0.0103 & 0.0077 & 0.0071 & -0.0200 \\
\hline & Personal situation & $(0.0722)$ & $(0.2193)^{*}$ & $(0.0353)$ & $(-0.0943)$ & $(0.0470)$ & $(0.0478)$ & $(-0.3438)^{*}$ \\
\hline & Jevel of Fducration & -0.0021 & 0.0056 & 0.0115 & 0.0127 & 0.0175 & 0.0155 & 0.0056 \\
\hline & Level of Education & $(-0.0244)$ & $(0.0985)^{* * * *}$ & $(0.1151)^{* * * *}$ & $(0.1098)^{* * * *}$ & $(0.1084)^{* * *}$ & $(0.1059)^{* * * *}$ & $(0.0867)^{* * * *}$ \\
\hline & & 0.0166 & 0.0109 & 0.0129 & 0.0204 & 0.0218 & 0.0232 & 0.0111 \\
\hline & ncerts & $(0.1900)^{* * * *}$ & $(0.1907)^{* * * *}$ & $(0.1294)^{* * * *}$ & $(0.1763)^{\text {**** }}$ & $(0.1347)^{* * *}$ & $(0.1581)^{* * * *}$ & $(0.1706)^{* * * *}$ \\
\hline & Other interest & 0.0059 & 0.0057 & 0.0036 & 0.0019 & 0.0063 & 0.0100 & 0.0030 \\
\hline & & $(0.0681)^{\text {**** }}$ & $(0.1003)^{* * * *}$ & $(0.0361)^{*}$ & $(0.0165)$ & $(0.0394)^{* *}$ & $(0.0685)^{* * * *}$ & $(0.0471)^{* * k}$ \\
\hline
\end{tabular}

Note: $* * *, * * *$ represent significance at $10 \%, 5 \%$ and $1 \%$ respectively.

Source: own elaboration. Data EHPC 2018-2019.

At the outset, it should be noted that it was not possible to run the regression for the 15 24 age group for zarzuela due to the small number of participants. There are three ways to analyze the observed data. It can be analyzed for each of the performing arts, for each of the regressors or age group.

When observing the data from the first and second approaches, that is, attending to the type of art and the regressors, the above data show that the behavior of the variables in each of the performing arts for each of the age groups is not homogeneous among the different arts, despite presenting certain analogies. This shows that among the performing arts there are particularities and singularities that differentiate them from each other. This question raises the need for studies on each of the arts.

Among the common characteristics for the arts is that interest in the specific art is always significant and positive. Indicating that greater interest in the activity increases the likelihood of participation. The slopes are generally ordered in the same way in all age groups, from highest to lowest the order would be theater, ballet, concerts, opera, and zarzuela.

The results by age group and performing arts reinforce what was previously stated about the presence of the time limitation in participation, in such a way that interest in the rest of the arts negatively affects participation in the specific art. The exception is found in concerts, for which interest in the rest of the arts increases the probability of participation; it can be justified that it is a more versatile art, which brings together characteristics of the others. It is therefore important to conduct studies on the characteristics that make up each of the arts and from which consumers derive their utility.

The results also reinforce what was already stated in the general model about the effect of education, which tends to be significant with positive slopes and with lower values than those corresponding to interest in the specific art.

Analyzing the data from the age groups, in the two older groups, the effect of interest and education also reinforces what was indicated by the general model; in such a way that both variables are significant with a positive slope. On the other hand, interest in the rest of the arts loses significance. This circumstance is explained by the elimination of the time restriction at these ages. The exception is found in concerts, whose interest in the other arts is significant with a positive slope. Ballet with a negative slope and opera with a positive slope present less significant degrees of significance. 
The behavior of the personal situation variable is also interesting. This variable is significant only for theater in the 25-44 age groups, concerts for the 25-34 age group, and for those over 75 in ballet, zarzuela and concert activities. But the sign of the slope is different, so for the elderly this slope is negative and for the others it is positive. This could be explained by the fact that in the younger age groups, not having a burden increases the probability of participation in theater and concerts, since they have more time available for leisure. For those over 75 years of age, having burdens increases the probability of participation, since the time restriction has disappeared, and it is also probable that there is a beneficial effect on cultural consumption in company. Among those over 75 years of age, the population living alone is very high, which reinforces the hypothesis that living in company increases the probability of attending cultural activities.

In the very old group, for Opera and Concerts, the employment status variable is significant to some degree and has positive slopes. Being active at these ages increases the probability of participating in both arts, reinforcing the importance of the reference groups.

As a rule, the slopes of the variable of interest fall in the older age groups with respect to the rest of the age groups, mainly those over 75 years of age ${ }^{7}$.

\section{CONCLUSIONS AND FUTURE LINES OF RESEARCH}

With the data analyzed, it can be concluded that the performing arts present their own characteristics that distinguish them from each other. It would be interesting to be able to apply Lancaster (1966)'s theoretical model of the characteristics, where the different goods would be replaced by their characteristics, understanding that the utility comes from the characteristics and not from the goods directly.

In the 35-44 age group, the work situation shows positive values, and in the case of theater and ballet, significant values, which can be explained by the idea that the environment enhances participation. At these ages, full integration into the labor market occurs, and the effect of the work group may facilitate cultural participation. The relationship between the work environment and cultural participation remains to be studied in future studies. For just as the family environment is important in explaining participation, the work environment must also have an influence on participation. This would justify the drop in interest and participation in the elderly and very elderly, as they lose part of their social relations with the exit of the labor market and family loneliness.

This paper contributes to the economics of culture literature by presenting empirical evidence on the impact of time use restriction as a determinant of participation in cultural activities, in this case for participation in performing arts. In the case of the very old, no significant differences are observed because there is no such time restriction. Only in ballet is it significantly negative, and in concerts it is significantly positive.

For future research, creating a specific cultural capital index using the survey data instead of human capital as a proxy for this variable has been scheduled; and to use other regressions, such as zero-truncated and tobit models. Since data from other years are available, design a pseudo panel to be able to compare the effects when consumption patterns are observed over time instead of using cross-sections of data, what would allow correcting possible endogeneity problems in the sample. 


\section{ORCID}

Blas Díaz León (iD https://orcid.org/0000-0003-0990-3508

Ignacio Martínez Fernández (iD) https://orcid.org/0000-0002-3856-1001

Luis Palma Martos (iD https://orcid.org/0000-0001-5834-3629

\section{References}

Abbé-Decarroux, F. (1993). La consummation Culturelle et les processus de la formation des goûts. Revue suisse de sociologie, 19(3), 589-618.

Abbé-Decarroux, F. (1995). Demande artistique et preferences endogenes. Revue Economique (Paris), 46(3), 983-992. http://dx.doi.org/10.3406/reco.1995.409715

Aguado, L., \& Palma, L. (2015). Factores que limitan la participacion cultural. Una mirada desde la economia de la cultura. Revista de Ciencias Sociales, XXI(1), 58-71.

Aguado, L., Palma, L., \& Pulido, N. (2017). 50 anos de Economia de la Cultura. Explorando sus raices en la Historia del Pensamiento Economico. Cuadernos de Economia (Santiago, Chile), 36(70), 197-225. http://dx.doi.org/10.15446/cuad.econ.v36n70.53813

Ateca-Amestoy, V. (2008). Determining heterogeneous behavior for theater attendance. Journal of Cultural Economics, 32(2), 127-151. http://dx.doi.org/10.1007/s10824-008-9065-Z

Ateca-Amestoy, V. (2009). El capital humano como determinante del consumo cultural. Estudios de Economía Aplicada, 27(1), 87-110.

Ateca-Amestoy, V. (2017). Si la participación cultural no es inclusiva, se corre el riesgo de que el consumo cultural de los más ricos se financie con los impuestos de todos. Campusa. Noticias de la Universidad del País Vasco. Retrieved from https://www.ehu.eus/es/-/n_20171013_participacion-cultural-ue

Becker, G. S. (1965). A Theory of the Allocation of Time. Economic Journal (London), 75(299), 493-517. http://dx.doi.org/10.2307/2228949

Becker, G. S., \& Murphy, K. M. (1988). A Theory of Rational Addiction. Journal of Political Economy, 96(4), 675-700. http://dx.doi.org/10.1086/261558

Borgonovi, F. (2004). Performing arts attendance: An economic approach. Applied Economics, 36(17), 18711885. http://dx.doi.org/10.1080/0003684042000264010

Brook, O. (2013). Reframing models of arts attendance: Understanding the role of access to a venue. The case of opera in London. Cultural Trends, 22(2), 97-107. http://dx.doi.org/10.1080/09548963.2013.783175

Buigut, S., \& Amaize, O. (2020). Determinants of theatre, dance, and art museum attendance in the United Arab Emirates. Journal of Heritage Tourism, 15(6), 612-625. http://dx.doi.org/10.1080/1743873X.2020.1719117

Chan, T. W., \& Goldthorpe, J. H. (2005). The social stratification of theatre, dance and cinema attendance. Cultural Trends, 14(3), 193-212. http://dx.doi.org/10.1080/09548960500436774

Courty, P., \& Zhang, F. (2018). Cultural participation in major Chinese cities. Journal of Cultural Economics, 42(4), 543-592. http://dx.doi.org/10.1007/s10824-018-9319-3

De la Vega, P., Suarez-Fernandez, S., Boto-Garcia, D., \& Prieto-Rodriguez, J. (2020). Playing a play: Online and live performing arts consumers profiles and the role of supply constraints. Journal of Cultural Economics, 44(3), 425-450. http://dx.doi.org/10.1007/s10824-019-09367-y

Diniz, S. C., \& Machado, A. F. (2011). Analysis of the consumption of artistic-cultural goods and services in Brazil. Journal of Cultural Economics, 35(1), 1-18. http://dx.doi.org/10.1007/s10824-010-9129-8

Espinosa Espinosa, A., \& Palma Martos, L. (2019). Cultural Participation in the Main Colombian cities, 20082015. Scientific Annals of Economics and Business, 66(SI1), 37-58. http://dx.doi.org/10.47743/saeb2019-0021

Falk, M., \& Katz-Gerro, T. (2016). Cultural participation in Europe: Can we identify common determinants? Journal of Cultural Economics, 40(2), 127-162. http://dx.doi.org/10.1007/s10824-015-9242-9

Foote, J. A. (2002). Cultural consumption and participation. Canadian Journal of Communication, 27(2/3), 209-220. http://dx.doi.org/10.22230/cjc.2002v27n2a1295 
Glevarec, H., Nowak, R., \& Mahut, D. (2020). Tastes of our time: Analysing age cohort effects in the contemporary distribution of music tastes. Cultural Trends, 29(3), 182-198. http://dx.doi.org/10.1080/09548963.2020.1773247

Grisolía, J. M., Willis, K., Wymer, C., \& Law, A. (2010). Social engagement and regional theatre: Patterns of theatre attendance. Cultural Trends, 19(3), 225-244. http://dx.doi.org/10.1080/09548963.2010.495277

Hallmann, K., Artime, C. M., Breuer, C., Dallmeyer, S., \& Metz, M. (2017). Leisure participation: Modelling the decision to engage in sports and culture. Journal of Cultural Economics, 41(4), 467-487. http://dx.doi.org/10.1007/s10824-016-9275-8

Heredia-Carroza, J., Palma Martos, L., \& Marin, A. (2020). Determinants of attendance frequency to flamenco shows in Spain. A cultural economic approach. Revista de Métodos Cuantitativos para la Economía y la Empresa, 29, 79-98. http://dx.doi.org/10.46661/revmetodoscuanteconempresa.3751

Katz-Gerro, T., Raz, S., \& Yaish, M. (2009). How do class, status, ethnicity, and religiosity shape cultural omnivorousness in Israel? Journal of Cultural Economics, 33(1), 1-17. http://dx.doi.org/10.1007/s10824-008-9088-5

Lancaster, K. (1966). A new approach to consumer theory. Journal of Political Economy, 74(2), 132-157. http://dx.doi.org/10.1086/259131

Levy-Garboua, L., \& Montmarquette, C. (2005). La demanda. In R. Towse (Ed.), Manual de Economía de la Cultura (pp. 179-198). Madrid: Fundación Autor.

Lévy-Garboua, L., \& Montmarquette, C. (1996). A microeconometric study of theatre demand. Journal of Cultural Economics, 20(1), 25-50. http://dx.doi.org/10.1007/s10824-005-5050-y

McCain, R. (2005). La formacion del gusto. In R. Towse (Ed.), Manual de Economia de la Cultura (pp. 371379): Fundacion Autor.

McCain, R. (2006). Defining Cultural and Artistic Goods. In V. Ginsburgh \& D. Throsby (Eds.), Handbook of the Economics of Art and Culture (pp. 147-167): Elsevier.

Miles, A., \& Sullivan, A. (2012). Understanding participation in culture and sport: Mixing methods, reordering knowledges. Cultural Trends, 21(4), 311-324. http://dx.doi.org/10.1080/09548963.2012.726795

Palma, M. L., Palma, L., \& Aguado, L. F. (2013). Determinants of cultural and popular celebration attendance: The case study of Seville Spring Fiestas. Journal of Cultural Economics, 37(1), 87-107. http://dx.doi.org/10.1007/s10824-012-9167-5

Prieto Rodríguez, J., Pérez Villadóniga, M. J., \& Suárez Fernández, S. (2018). El consumo cultural: ¿cuestión de gusto o de precio? Observatorio Social de "La Caixa". Retrieved from https://observatoriosociallacaixa.org/-/el-consumo-cultural_cuestion-de-gusto-o-de-precio

Reeves, A. (2014). Cultural engagement across the life course: Examining age-period-cohort effects. Cultural Trends, 23(4), 273-289. http://dx.doi.org/10.1080/09548963.2014.961274

Scherger, S. (2009). Cultural practices, age and the life course. Cultural Trends, 18(1), 23-45. http://dx.doi.org/10.1080/09548960802651203

Stigler, G. J., \& Becker, G. S. (1977). De gustibus non est disputandum. The American Economic Review, 67(2), 76-90.

Suárez-Fernández, S., Prieto-Rodríguez, J., \& Pérez-Villadoniga, M. J. (2020). The changing role of education as we move from popular to highbrow culture. Journal of Cultural Economics, 44(2), 189-212. http://dx.doi.org/10.1007/s10824-019-09355-2

Upright, C. B. (2004). Social capital and cultural participation: Spousal influences on attendance at arts events. Poetics, 32, 129-143. http://dx.doi.org/10.1016/j.poetic.2004.02.002

Van den Broek, A. (2013). Arts participation and the three faces of time: A reflection on disentangling the impact of life stage, period and socialization on arts participation, exemplified by an analysis of the US arts audience. Cultural Trends, 22(1), 46-53. http://dx.doi.org/10.1080/09548963.2013.757898

Wen, W.-J., \& Cheng, T.-C. (2013). Performing arts attendance in Taiwan: who and how often? Journal of Cultural Economics, 37(2), 309-325. http://dx.doi.org/10.1007/s10824-012-9180-8 
Scientific Annals of Economics and Business, 2021, Volume 68, Special Issue, pp. 35-52 51

\section{ANNEX}

Main statistics

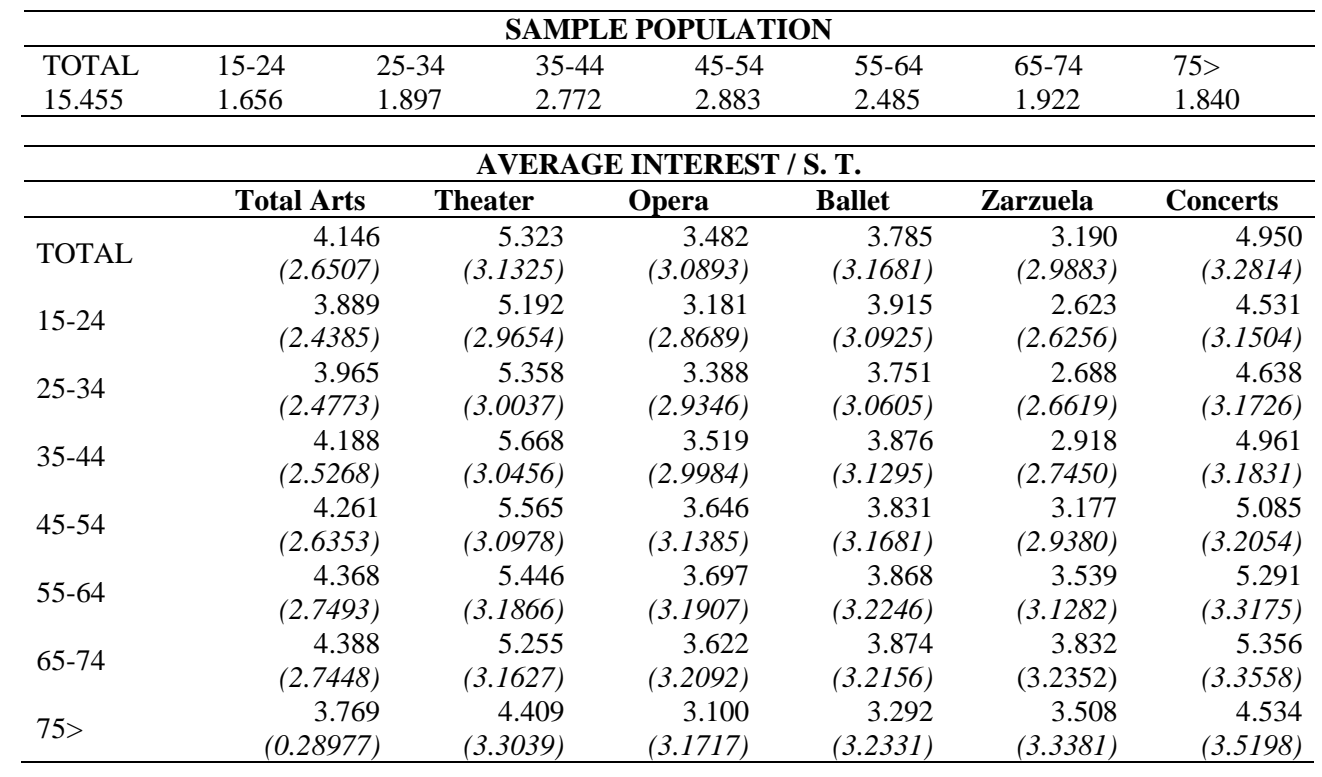

\begin{tabular}{|c|c|c|c|c|c|c|}
\hline \multicolumn{7}{|c|}{ PERCENTAGE OF POPULATION PARTICIPATING / S. D. } \\
\hline & Total Arts & Theater & Opera & Ballet & Zarzuela & Concerts \\
\hline \multirow{2}{*}{ TOTAL } & 31,47 & 24,846 & 3,286 & 8,087 & 1,643 & 9,563 \\
\hline & $(0.46442)$ & $(0.24846)$ & $(0.03287)$ & $(0.08088)$ & $(0.016435)$ & $(0.096538)$ \\
\hline \multirow{2}{*}{$15-24$} & 37,198 & 31,582 & 2,898 & 10,024 & 1,026 & 7,910 \\
\hline & $(0.48348)$ & $(0.46498)$ & $(0.16782)$ & $(0.30041)$ & $(0.10083)$ & $(0.26999)$ \\
\hline \multirow{2}{*}{$25-34$} & 32,261 & 28,044 & 3,110 & 8,539 & 1,054 & 7,063 \\
\hline & $(0.46760)$ & $(0.44933)$ & $(0.17364)$ & $(0.27955)$ & $(0.10216)$ & $(0.25629)$ \\
\hline \multirow{2}{*}{$35-44$} & 34,740 & 28,968 & 2,597 & 9,523 & 0,757 & 7,683 \\
\hline & $(0.47623)$ & $(0.45370)$ & $(0.15909)$ & $(0.29360)$ & $(0.086724)$ & $(0.26639)$ \\
\hline \multirow{2}{*}{$45-54$} & 33,818 & 26,500 & 2,878 & 8,359 & 1,040 & 9,989 \\
\hline & $(0.47318)$ & $(0.44141)$ & $(0.16724)$ & $(0.27683)$ & $(0.10149)$ & $(0.29991)$ \\
\hline \multirow{2}{*}{$55-64$} & 34,164 & 26,277 & 4,708 & 8,531 & 2,374 & 13,360 \\
\hline & $(0.47436)$ & $(0.44023)$ & $(0.21186)$ & $(0.27940)$ & $(0.15228)$ & $(0.34029)$ \\
\hline \multirow{2}{*}{$65-74$} & 30,176 & 21,436 & 4,890 & 7,544 & 3,277 & 13,579 \\
\hline & $(0.45915)$ & $(0.41048)$ & $(0.21573)$ & $(0.26417)$ & $(0.17810)$ & $(0.4266)$ \\
\hline \multirow{2}{*}{ 75> } & 14,619 & 8,315 & 1,902 & 3,260 & 2,391 & 7,228 \\
\hline & $(0.35340)$ & $(0.27619)$ & $(0.13664)$ & $(0.17766)$ & $(0.15282)$ & $(0.25903)$ \\
\hline \multicolumn{7}{|c|}{ INTEREST/EDUCATION CORRELATION } \\
\hline & Theater & Opera & Ballet & & Zarzuela & Concerts \\
\hline TOTAL & 0,3002 & 0,2617 & & 0,2356 & 0,1688 & 0,2264 \\
\hline $15-24$ & 0,2533 & 0,2590 & & 0,2097 & 0,1860 & 0,1978 \\
\hline $25-34$ & 0,3351 & 0,3303 & & 0,3050 & 0,2225 & 0,3013 \\
\hline $35-44$ & 0,3099 & 0,2525 & & 0,2239 & 0,1560 & 0,2150 \\
\hline $45-54$ & 0,2355 & 0,1873 & & 0,1672 & 0,0647 & 0,1465 \\
\hline $55-64$ & 0,3906 & 0,3652 & & 0,3459 & 0,2868 & 0,3426 \\
\hline $65-74$ & 0,3079 & 0,2391 & & 0,2255 & 0,1538 & 0,2594 \\
\hline 75 & 0,2744 & 0,2124 & & 0,1789 & 0,1211 & 0,1201 \\
\hline
\end{tabular}




\section{Notes}

${ }^{1}$ From now on, Theater, Opera, Ballet, Zarzuela and Classical Music Concerts will be indicated as Performing Arts.

${ }^{2}$ See Aguado and Palma (2015).

${ }^{3}$ In an interview dated 10/13/2017 in Campusa, News from the University of the Basque Country.

${ }^{4}$ The main statistics of the variables used can be consulted in the annex.

${ }^{5}$ Zarzuela is a typical Spanish musical genre close to opera but with some differences.

${ }^{6}$ The program used to perform the regressions is Gretl.

${ }^{7}$ The appendix shows the sharp drop in interest among those over 75 years of age.

\section{Copyright}

cc) (i) $(-)$ This article is an open access article distributed under the terms and conditions of the Creative Commons Attribution-NonCommercial-NoDerivatives 4.0 International License. 